\title{
Research on the Concrete Pump Hydraulic System
}

\author{
Qing Zhao ${ }^{1, \text { a }}$,Lijun $\mathrm{Li}^{1, \mathrm{~b}}$, Qiang $\mathrm{Han}^{2, \mathrm{c}}$ \\ ${ }^{1}$ School of Mechanical and Electronic, Central south University of Forestry and Technology, \\ Changsha, 410004,Hunan, P.R.China \\ ${ }^{2}$ China Railway Construction Heavy Industry Co,LTD. \\ Changsha, 410100 , Hunan,P.R.China

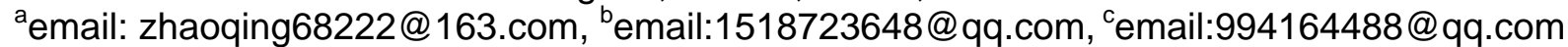

Keywords: concrete delivery pump; hydraulic system; reliability

\begin{abstract}
For improving the reliability of the concerte pump,a reliable hydraulic system is required. In this paper,a new concrete pump hydraulic system was designed to achieve single pump driving multiple load. The proposed hydraulic system had four parallel pump, and ensured that when one pump failured, the hydraulic system can still work. The analyzed results show that the proposed hydraulic system is a feasible and effective for ensuring the reliability of the concerte pump.
\end{abstract}

\section{Introduction}

Concrete pump is a special machinery for transporting and pouring concrete, which it is equipped with a special pipe can be continuously fed into the pipeline along the concrete pouring site[1][2], especially in high-rise buildings, underground buildings and large concrete structures construction project.With the high-quality, high efficiency, low consumption, low cost, short construction period, low labor intensity, concrete pump gradually becomed an indispensable construction of key equipment.

The hydraulic system is an important part of the concrete pump,affecting the performance of the machine.However,the existing concrete pump hydraulic system showed some problems, focusing on the main pumping circuit and the swing cylinder circuit[3].

\section{Problem Description}

\section{Main pumping circuit}

Fig.1 shows the exist concrete pump hydraulic system main pumping circuit. Main pump 2 output pressure oil through hydraulic valve 6 into the main pumping cylinder 9 or 10, in order to achieve the pumping operations.The circuit can be achieved on the main pumping cyclinders 9 and 10 operations control.

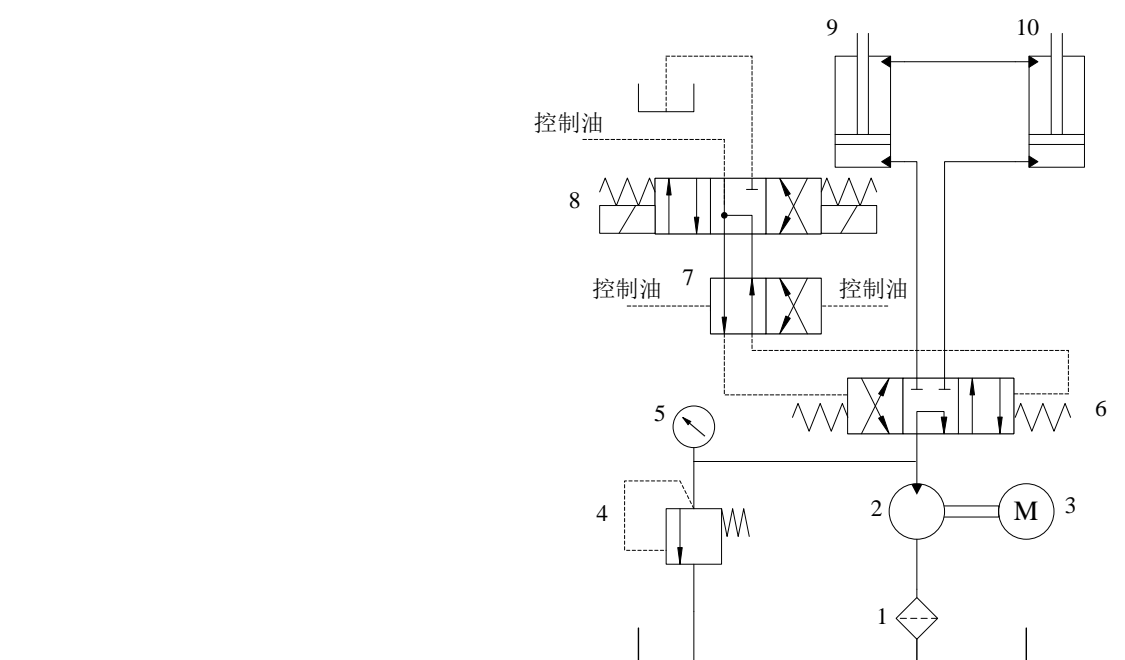

1-Suction filer; 2-Main pump; 3-Motor; 4- Pressure relief valve; 5- pressure gauge; 6、7-Hydraulic operated directional valve; 8-Electromagnetic directional valves; 9、10-Main cylinder;

Fig.1 Main pumping circuit 
1. Main pump reversing impact

The system pressure can reach 30MPA when the hydraulic circuit works in the high-pressure pumping system. When the main pumping cylinder 9 and 10 reversing,the valve element of hydraulic operated directional valve 6 instant move from left to right, at this time, high-pressure oil and the main pumping cylinder 9 or 10 of the rear end will turn on instantly with the reservoir, the pressure from the moment 30MPA reduced to 0, resulting in reversing impact[4].

2. Reduce pumping ability and efficiency

Table 1 Main pumping ciecuit parameters

\begin{tabular}{cccc}
\hline S valve revering time & Pumping circuit unloading time & Pumping frequence & Each pumping cycle \\
\hline $0.3 \mathrm{~s}-0.4 \mathrm{~s}$ & $0.3 \mathrm{~s}-0.4 \mathrm{~s}$ & $15-30 / \mathrm{min}$ & $2 \mathrm{~s}-4 \mathrm{~s}$ \\
\hline
\end{tabular}

Pumping circuit unloading time is $0.3 \mathrm{~s}-0.4 \mathrm{~s}$, pumping frequency is $15-30 / \mathrm{min}$, and then the time of each pumping cycle is $2 \mathrm{~s}-4 \mathrm{~s}$. Therefore,the pumping ability reduced more than $10 \%$.

When the pumping frequence less than $30 / \mathrm{min}$,the excess oil will be back to resevoir through the pressure relief valve, oil flow of main pump will not been fully utilized,and the efficiency of pumping will be reduced.

\section{Swing cylinder circuit}

Fig.2 shows the exist concrete pump hydraulic system swing cylinder circuit. Pressure compensated pump 2 output pressure oil through hydraulic valve 6 into the swing cylinder 9 or 10 , in order to achieve the $\mathrm{S}$ valve revesing operations.The circuit can be achieved on the swing cyclinders 9 and 10 operations control[5].

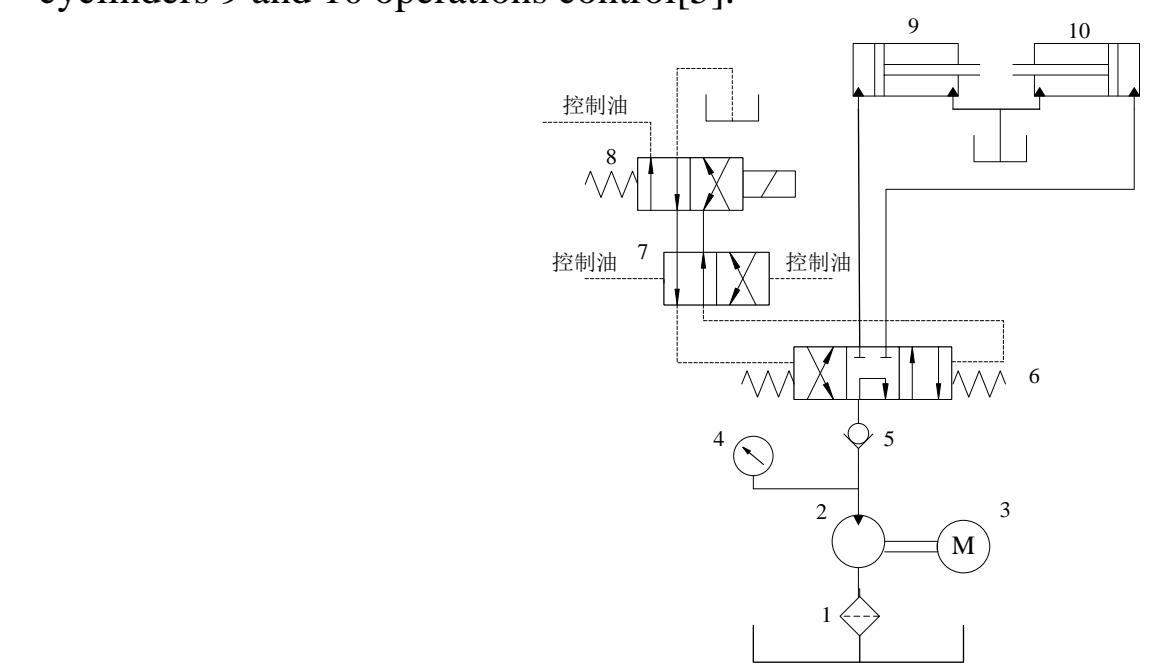

1-Suction filer; 2-Pressure compensated pump; 3-Motor; 4- pressure gauge; 5-Check valve; 6、7-Hydraulic operated directional valve; 8-Electromagnetic directional valves; 9、10-Swing cylinder;

Fig.2 Swing cylinder circuit

1. Pressure compensated pump's variable mechanism easily damaged

According to the $\mathrm{S}$ valve revesering characteristics, the variable mechanism、plunger、shoes、 valve plate and other sports deputy of pressure compensated pump will be subjected to high pressure to low pressure frequently,so that the pressure compensated pump easily damage as the main pump.

2. S valve could not work

S valve reversing circuit was oiled by the pressure compensated pump,and the working pressure is generally 16-19MPa.But when the concrete slumped,the resistance of the swing cylinder increased.If the pressure more than 19MPa,the swing cylinder would not work, with the pressure compensated pump life sharply reduced.

\section{Solution}

A new concrete pump hydraulic system was designed,and could solve the above problems. The new concrete pump hydraulic system is shown in Fig.3. 


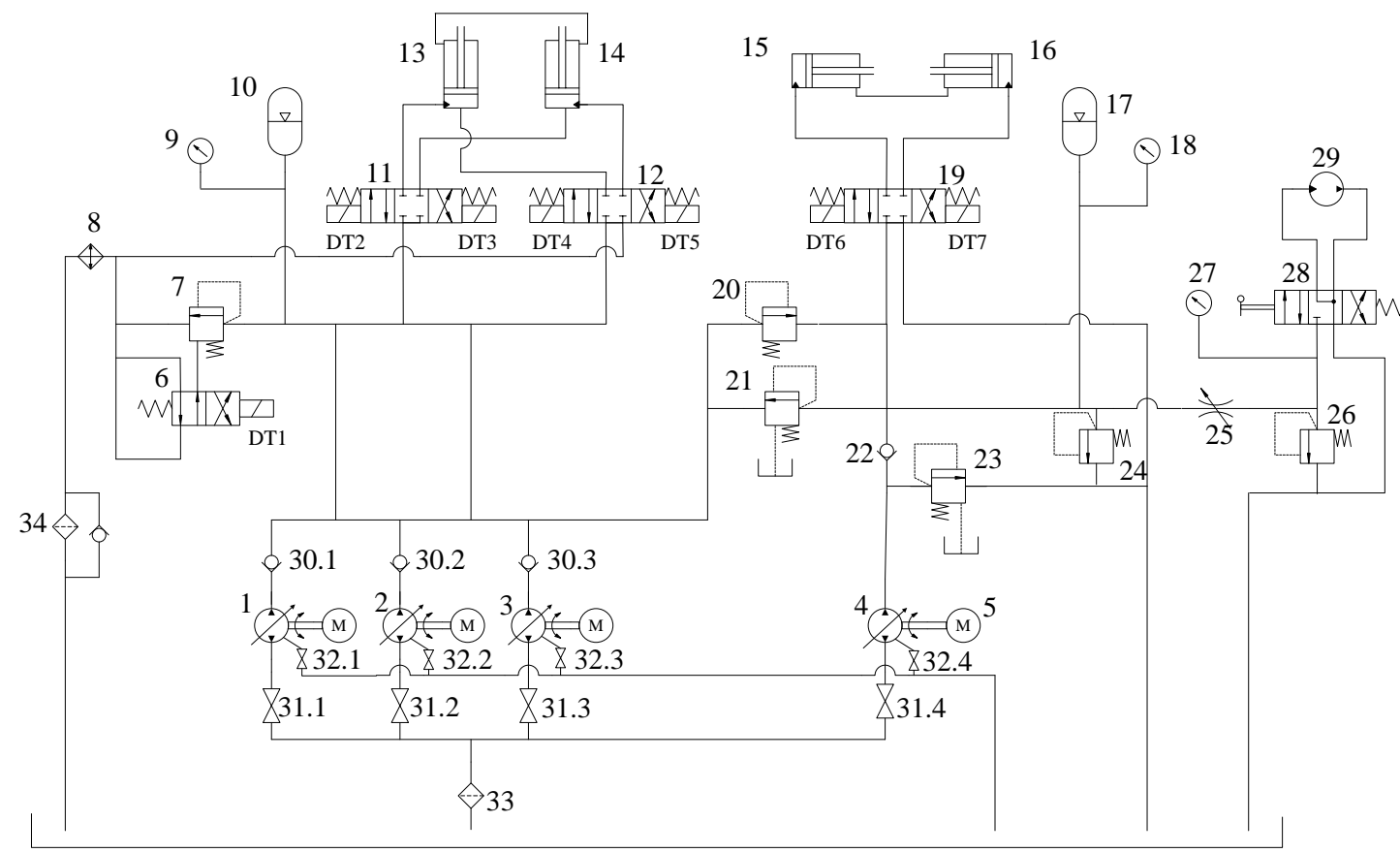

1、2、3、4

Variable pump; 5-Motor; 6- Electromagnetic directional valves; 7-Pressure relief valve; 8-cooler; 9-Pressure gauge; 10-Energy accumulator; 11、12-Electromagnetic directional valves; 13、14-Main cylinder; 15、16-Swing cylinder; 17- Energy accumulator; 18-Pressure gauge; 19-Electromagnetic directional valves; 20-Pressure reducing valve; 21-Pressure relief valve; 22-Check velve; 23-Pressure relief valve; 24-Sequence valve; 25-Throttle valve; 26- Pressure relief valve; 27-Pressrue guage; 28-Manually operated valve; 29-Mixing motor; 30-Check valve; 31、32-Shut-off valve; 33-Suction filer; 34-Return oil filer;

Fig.3 The new concrete pump hydraulic system

The new concrete pump hydraulic system had some advantages, with the mian pump and pressure compensated pump confluence, main pump pressure compensated swing cylinder,and single pump could ensure the normal work.Therefore the reliabity of the new concrete pump hydraulic system will greatly improve.

1. main pump and pressure compensated pump confluence

When the working pressure of main pumping circuit below a certain pressure,the swing cylinder circuit would compensate the pressure through the sequence valve 24 to achieve the main pump and pressure compensated pump confluencing, accelerating the pumping speed, and improving the pumping efficiency.

2. main pump pressure compensated swing cylinder

When the swing cylinder in the event of low slump concrete,the pressure of the swing circuit could not be required.At this time,the new concrete pump hydraulic system can open the shut-off valve 31 between main pumping system and swing cylinder pumping system, and pumping high-pressure oil to achieve the main pump pressure compensate swing cylinder.

3. single pump ensured the normal work

When one pump is damaged,the main pumping circuit 、 the swing cylinder circuit and the stiring circuit would communicate.So that only one pump is working in normal,the concrete pump will work.It is greatly improving the reliability and stability of the new concrete pump.

\section{Conclusion}

Concrete pump chassis of the vehicle is carrying a concrete mixing equipment, transportation, integrated cleaning device is incorporated by pipeline to achieve precise positioning coordinate long-range transport; hydraulic components are widely used on the market in Germany Rexroth and other import brands, new concrete pump made use of Beijing Ward and Shaoyang Vick hydraulic components, hydraulic system reduced the price by half, and by creating a prototype, test carried out construction, the initial realization of the hydraulic system 1000 hours without failure tracking feedback. 


\section{Acknowledgement}

In this paper, the research was sponsored by the Scientific Research Fund of Hunan Provincial Education Department (Project No. 14C1162) and Youth Science Research Foundation of Central South University of Forestry and Technology (Project No. QJ201509).

\section{References}

[1]Wang Anlin,Shi Zhongqiu. Based on MATLAB/Simscape Concrete Pump Hydraulic System Dynamic Modeling and Simulation Analysis[A]. Proceedings of 2009 International Conference on Advances in Construction Machinery and Vehicle Eegineering[C]. 2009.

[2]Bhupinder Singh,S.P.Singh,Bikramjit Singh.Some Issues Related to Pumpinig of Concrete[J]. The Indian Concrete Journal,2004(9), 41-44.

[3]Zhao Jing-yi,Yao Cheng-yu.Hydraulic System Reliability Engineering[M], Beijing: Mechanical Industry Press, 2011.

[4]Wu Wan-rong,Mao Zhen-wen,Huang Xiang-yang.Study on Control Method for Hydraulic Impact of Open Hydraulic System in Concrete Pump[J],Computer Simulation,2014,31,(11)222-226.

[5]Wang wen-hongThe Design of Hydraulic System for HBT60 Concrete Pump[J], Chinese Hydraulics and Pneumatics.2009, (10):63-65. 